\title{
An Empirical Study of Production-oriented Approach in College English Writing Teaching
}

\author{
Xu Liu ${ }^{1}$, He Yingjie ${ }^{1}$, Zhou Zhen ${ }^{2, *}$ \\ ${ }^{1}$ Wuhan School Attached to Beijing Normal University, Wuhan, 430040, Hubei, China \\ ${ }^{2}$ Professor of Ningxia University, Ningxia University, Yinchuan, 750021, Ningxia Hui Autonomous Region, China
}

Received August 30, 2020; Revised October 12, 2020; Accepted November 1, 2020

\begin{abstract}
Cite This Paper in the following Citation Styles
(a): [1] Xu Liu, He Yingjie, Zhou Zhen, "An Empirical Study of Production-oriented Approach in College English Writing Teaching," Universal Journal of Educational Research, Vol. 8, No. 11B, pp. 6173 - 6177, 2020. DOI: 10.13189/ujer.2020.082254.
\end{abstract}

(b): Xu Liu, He Yingjie, Zhou Zhen (2020). An Empirical Study of Production-oriented Approach in College English Writing Teaching. Universal Journal of Educational Research, 8(11B), 6173 - 6177. DOI: 10.13189/ujer.2020.082254.

Copyright $\bigcirc 2020$ by authors, all rights reserved. Authors agree that this article remains permanently open access under the terms of the Creative Commons Attribution License 4.0 International License

\begin{abstract}
Production-oriented approach" (POA) is a foreign language teaching theory put forward by Chinese professor Wen Qiufang and her team. The theoretical system of POA consists of teaching concept, teaching hypothesis and teaching process with the role of teachers' mediation, aiming at solving the problem of "separation between learning and using" and enhancing foreign language teaching effectiveness in college. The empirical experiment has been conducted in a university in Ningxia Hui Autonomous Region for 15 weeks, and 110 sophomores of two parallel classes participate in the research with 55 students in each class. They are taught by the same teacher with the same teaching materials in both experimental class (EC) and control class (CC). The only difference is that $\mathrm{EC}$ is taught by POA, while $\mathrm{CC}$ is taught by traditional writing approach that is product writing approach (PWA). Furthermore, questionnaires and writing tests are implemented in $\mathrm{CC}$ and EC, as well as Statistic Package for Social Science (SPSS) 17.0 is used to collect and analyze data. The research reveals that POA is more effective to help students master English writing strategies than PWA. Meanwhile, POA is more capable to improve students' language accuracy and increase the output of targeted connectives significantly instead of syntactic complexity of clause in English writing. Regarding writing scores, there is no significant difference between $\mathrm{CC}$ and EC which is consistent with the research results gotten by Zhang [20]. At last, some insightful suggestions and implications are proposed for future study.
\end{abstract}

Keywords Production-oriented Approach, English
Writing, Writing Scores

\section{Introduction}

English writing is a comprehensive process of output, which combines many factors together, such as vocabulary, grammar, discourse, contents, cohesion and so forth. According to relative researches, Sheng and Feng [7] claim that most of the Chinese students are poor at English writing. Besides, it turns out English writing teaching is almost exam-oriented with a lack of natural cultivation of English writing ability. When students focus on English writing, they just finish the tasks assigned by teachers, or meet the requirements of a variety of tests, just like test for English major 4 (TEM4) and the like. Based on the findings of some experiments, Zhang and Tao [22] reveal that students have great difficulty in the process of writing even though they have mastered certain words, proficient grammars and some connectives.

Product writing approach, process writing approach, lengthy approach and so on are applied to English teaching in China, however, students' needs cannot be satisfied and the teaching is not effective. As for the features of these writing approaches, the product writing approach is beneficial for students to have a good command of the accurate words, correct grammars, right sentence patterns and appropriate discourse structures; nevertheless, it carries some salient drawbacks, such as extreme emphasis 
upon teacher-centered roles, simple assessments and feedback for compositions, shortage of enough time for students to have deep thoughts about topics, as well as a lack of teacher-student communication. Compared with the first approach, the process writing approach possesses many features, consisting of the teachers' facilitating roles, objective evaluation, more attention to students' creativity and potential. However, as to the implementation of the approach, Han and Qin [2] asserted that teachers often ignore the genre of articles and language input. Meanwhile, the lengthy approach was proposed by Wang et al. [9], which claimed that teachers were supposed to encourage students to open their mind freely and get over emotional worry, then to come up with ideas to express themselves by adjusting the length of compositions. Nevertheless, students' learning motivations have not been strengthened, and there was a gap between evaluation model and expected effectiveness. According to the characteristics of these approaches, what English teachers should do is to take advantage of the strengths and avoid the shortcomings of them.

Each approach has its own advantages and disadvantages. Until now, some approaches have been introduced in China with few innovations made. Meanwhile, a plenty of scholars doubted that the English teaching approaches would be in the stage of "Post-Method" era or even the methods are impossible to be created Brown [1]. Therefore, Chinese professor Wen and her team members [13,14, 15, 16, 17, 18,19] devoted themselves to exploring and creating a new teaching method called "Production-oriented Approach", which featured Chinese characteristics, including integration of curriculum theory Tyler [8] and second language acquisition (SLA); persistence in "Practice is the only criterion to vet the truth"; specific solutions to certain problems and the emphasis of teachers' dominant roles [18, 19]. More importantly, POA has been localized in China, which will be easier to be comprehended, implemented, and developed in foreign language teaching.

\section{Research Design}

\subsection{Research Question}

(1) Compared with PWA, could POA change college students' English writing strategies significantly?

(2) Compared with PWA, could POA enhance college students' language accuracy, syntactic complexity of clause and the output of targeted connectives in English writing significantly?

(3) Compared with PWA, could POA improve college students' writing scores significantly?

\subsection{Research Participants}

The empirical study has been conducted in a university in Ningxia Hui Autonomous Region for 15 weeks. And 110 non-English major sophomores from two parallel classes participate in the research with 55 students in EC and CC respectively. During the empirical study, they are taught by the same teacher with the same teaching materials. The EC is taught by POA, while CC is PWA.

\subsection{Research Instruments}

Questionnaires and writing tests are implemented to collect and analyze by SPSS 17.0.

\subsubsection{Questionnaires}

Questionnaire is a meaningful tool for quantitative analysis in scientific research. In this thesis, the questionnaire has integrated Wen's [11] questionnaire format and Zhao's [21] some questionnaire questions with certain changes to figure out whether students' English writing strategies could be changed significantly by POA compared with PWA. Meanwhile, the value of Cronbach reaches 0.67 , which implies the questionnaire is reliable.

The questionnaire of the research is made up of two parts, including personal information and writing strategies. Specifically speaking, the first part of questionnaire is designed to collect some basic information of students, consisting of the name, gender, birth of place and English scores last semester. Then, the second part is connected to English writing strategies.

The researcher draws on Five-Point Likert scale to gauge all the propositions ranging from 1 to 5 ( 1 - strongly disagree, 2-disagree, 3-not sure, 4-agree, 5-strongly agree). At the same time, before the students make choices, the researcher guides them to have a better understanding of some questions. All the questionnaires are handed out and completed fully and collected meticulously.

\subsubsection{Writing Tests}

Test is a useful tool in the realm of research to measure participants' certain abilities in some aspects. In this study, the researcher uses three writing tests to collect enough data for studying whether POA could improve students' language accuracy, syntactic complexity of clause and the output of targeted connectives significantly, as well as research whether students' writing scores could be changed significantly by POA compared with PWA. In addition, the curriculum's aims and requirements of the university are the guidelines for the researcher to select the topics of writing tests.

The writing tests are implemented three times at the beginning, during the middle and at the end of the study respectively. The topics are chosen from the textbook called Start from Scratch. Then, the researcher integrates some methods from Wolfe-Quintero et al. [10] and Polio [5] to assess students' language accuracy, syntactic complexity of clause and the output of targeted connectives in English writing. To be more specific, the way to measure 
language accuracy refers to the ration of error-free t-units per total t-units; syntactic complexity of clause is the ration of clauses per total t-units as well as the output of targeted connectives is counted.

\section{Analysis and Results}

\subsection{Results and Analysis of Questionnaire in English Writing Strategies}

The questionnaire in English writing strategies consists of five questions, which is carried out before and after the experiment. Furthermore, the researcher demonstrates independent sample t-test to analyze the data of the pre-Q and post-Q, just as the table 1 shows below.

Table 1. Independent Sample t-Test of Pre-Q and Post-Q in English Writing Strategies between CC and EC

\begin{tabular}{|c|c|c|c|c|c|c|}
\hline $\begin{array}{c}\text { English } \\
\text { Writing } \\
\text { Strategies }\end{array}$ & Class & Mean & $\mathrm{N}$ & $\mathrm{df}$ & $\mathrm{T}$ & $\begin{array}{c}\text { Sig. } \\
(2- \\
\text { tailed }\end{array}$ \\
\hline \multirow{2}{*}{ Pre-Q } & $\mathrm{CC}$ & 15.89 & 55 & 108 & .075 & .940 \\
\cline { 2 - 7 } & $\mathrm{EC}$ & 15.95 & 55 & 108 & .075 & .940 \\
\hline \multirow{2}{*}{ Post-Q } & $\mathrm{CC}$ & 16.25 & 55 & 108 & 2.694 & .008 \\
\cline { 2 - 7 } & $\mathrm{EC}$ & 18.16 & 55 & 108 & 2.694 & .008 \\
\hline
\end{tabular}

The mean of scores in pre-Q is 15.89 in $\mathrm{CC}$ and 15.95 in $\mathrm{EC}$, and the mean in post-Q is 16.25 and 18.16 respectively; it can be seen that the mean of EC is higher than that of CC in post-Q with an increase 1.91(18.16-16.25). Meanwhile, the significant value $(\mathrm{p}=0.940)$ is higher than 0.05 in pre-Q, which means the mean between $\mathrm{CC}$ and $\mathrm{EC}$ is of no significant difference. Nevertheless, the significant value in post-Q is 0.008 , which is below 0.05 . It represents there is significant difference in English writing strategies between $\mathrm{CC}$ and EC after the experiment. Accordingly, it denotes that POA has a profound effect on English writing strategies compared with PWA.

\subsection{Results and Discussion of Writing Tests}

The data of writing tests are collected. The analysis are elucidated in the following parts, consisting of language accuracy, syntactic complexity of clause, the output of targeted connectives and students' writing scores.

\subsubsection{Results and Analysis of Language Accuracy}

In this study, the researcher draws on research methods put forward by Wolfe-Quintero et al. [10] to get the results and make related analysis of language accuracy. Specifically speaking, it is gauged by the ratio of error-free t-unit to total number of t-units in students' compositions. The types of errors include the lack of subject, predicative, the mistakes of tense, voice, spelling, phrase collaboration, grammar, and the like. The specific results of students' language accuracy are shown in table 2 as follows.
Table 2. Independent Sample t-Test of Language Accuracy in Pre-, Midand Post-test between $\mathrm{CC}$ and $\mathrm{EC}$

\begin{tabular}{|c|c|c|c|c|c|}
\hline & Class & Mean & df & T & Sig.(2-tailed) \\
\hline \multirow{3}{*}{ Pre-test } & $\mathrm{CC}$ & 0.761 & 108 & -0.614 & 0.540 \\
\cline { 2 - 6 } & $\mathrm{EC}$ & 0.742 & 108 & -0.614 & 0.540 \\
\hline \multirow{3}{*}{ Mid-test } & $\mathrm{CC}$ & 0.654 & 108 & 3.517 & 0.001 \\
\cline { 2 - 6 } & $\mathrm{EC}$ & 0.788 & 108 & 3.517 & 0.001 \\
\hline \multirow{3}{*}{ Post-test } & $\mathrm{CC}$ & 0.591 & 108 & 5.625 & 0.000 \\
\cline { 2 - 6 } & $\mathrm{EC}$ & 0.828 & 108 & 5.625 & 0.000 \\
\hline
\end{tabular}

The table 2 elucidates the mean of language accuracy of $\mathrm{CC}$ and EC in pre-, mid- and post-test. Concerning the mean scores in the pre-test and the mid-test, students in EC with an increase of $0.046(0.788-0.742)$ have made greater progress than CC with a decrease of 0.107 (0.761-0.654). Then, when it comes to the mean of language accuracy in mid- and post-test of $\mathrm{CC}$ and $\mathrm{EC}$, it is clear that $\mathrm{CC}$ has decreased by 0.063 (0.654-0.591), while EC has increased by $0.04(0.828-0.788)$. More importantly, compared the pre-test with post-test in $\mathrm{CC}$ and $\mathrm{EC}$, it is noted that $\mathrm{CC}$ has decreased by 0.170 (0.761-0.591); on the contrary, EC has rocketed by $0.086(0.828-0.742)$. Accordingly, POA has exerted greater impact on language accuracy than PWA.

There is no significant difference in language accuracy between $\mathrm{CC}$ and EC in pre-test, for the significant value $(p=0.540)$ is greater than 0.05 . During the mid-test, the significant value $(\mathrm{p}=0.001)$ is below 0.05 , which denotes the difference of language accuracy between EC and CC is significant; at the same time, the significant value in post-test $(p=0.000)$ is also below 0.05 that means there is significant difference in language accuracy between $\mathrm{CC}$ and EC.

To conclude, based on the analysis of independent sample t-test above, it is apparent that POA could help students to enhance language accuracy significantly compared with PWA.

\subsubsection{Results and Analysis of Syntactic Complexity of Clause}

Syntactic complexity of clause refers to the ration of clauses per t-units (Hunt, [4]; Halliday [3]; Wolfe-Quintero et al. [10]; Zhang Yiping [23]). The results of independent sample t-test in pre-, mid- and post-tests between $\mathrm{CC}$ and EC are shown in table 3 as follows.

Table 3. Independent Sample t-Test of Syntactic Complexity of Clause in Pre-, Mid- and Post-test between CC and EC

\begin{tabular}{|l|c|c|c|c|c|c|}
\hline & Class & Mean & $\mathrm{N}$ & $\mathrm{df}$ & $\mathrm{T}$ & Sig.(2-tailed) \\
\hline \multirow{3}{*}{ Pre-test } & $\mathrm{CC}$ & 1.267 & 55 & 108 & -0.259 & .796 \\
\cline { 2 - 7 } & $\mathrm{EC}$ & 1.256 & 55 & 108 & -0.259 & .796 \\
\hline \multirow{3}{*}{ Mid-test } & $\mathrm{CC}$ & 1.692 & 55 & 108 & -1.034 & .304 \\
\cline { 2 - 7 } & $\mathrm{EC}$ & 1.479 & 55 & 108 & -1.034 & .304 \\
\hline \multirow{3}{*}{ Post-test } & $\mathrm{CC}$ & 1.409 & 55 & 108 & 1.511 & .134 \\
\cline { 2 - 7 } & $\mathrm{EC}$ & 1.489 & 55 & 108 & 1.511 & .134 \\
\hline
\end{tabular}


The table 3 illustrates the means of syntactic complexity of clause in pre-test, mid-test and post-test in CC and EC. Obviously, in pre-test, it can be seen that CC and EC have similar mean of syntactic complexity of clause with 1.267 and 1.256 respectively. Compared with the pre-test, $\mathrm{CC}$ has more greatly increased by $0.425(1.692-1.267)$ than EC with 0.223 (1.479-1.256) in mid-test. Besides, with regard to the means of syntactic complexity of clause of $\mathrm{CC}$ and $\mathrm{EC}$ in post-test, compared with the mid-test, it is evident that CC has a large decrease by 0.283 (1.692-1.409); by contrast, EC has a slight increase by 0.01 (1.489-1.479).

Furthermore, based on the table 3, there are no significant differences in syntactic complexity of clause in pre-test, mid-test and post-test between CC and EC, as the significant values are much higher than $0.05(\mathrm{p}=0.796$, $\mathrm{p}=0.304, \mathrm{p}=0.134)$ respectively. More importantly, it can be inferred that POA does not have more significant advantage than PWA in enhancing writing syntactic complexity of clause between EC and CC.

All in all, according to the analysis of independent sample t-test in table 3 , there is no significant difference in the light of students' syntactic complexity of clause between CC and EC. In other words, POA has not played more obvious role in enhancing students' syntactic complexity of clause than PWA.

\subsubsection{Results and Analysis of the Output of Targeted Connectives}

The output of targeted connectives is counted to research whether students' output could be changed significantly by POA compared with PWA. The results of independent sample t-test between $\mathrm{CC}$ and $\mathrm{EC}$ in $\mathrm{CC}$ and $\mathrm{EC}$ are shown in table 4 as follows.

Table 4. Independent Sample t-Test of the Output of Targeted Connectives in Pre-, Mid- and Post-test between CC and EC

\begin{tabular}{|c|c|c|c|c|c|c|}
\hline & Class & Mean & $\mathrm{N}$ & $\mathrm{df}$ & $\mathrm{T}$ & Sig.(2-tailed) \\
\hline \multirow{3}{*}{ Pre-test } & $\mathrm{CC}$ & 7.45 & 55 & 108 & 0.406 & .685 \\
\cline { 2 - 7 } & $\mathrm{EC}$ & 7.64 & 55 & 108 & 0.406 & .685 \\
\hline \multirow{3}{*}{ Mid-test } & $\mathrm{CC}$ & 8.87 & 55 & 108 & -3.338 & .001 \\
\cline { 2 - 7 } & $\mathrm{EC}$ & 7.05 & 55 & 108 & -3.338 & .001 \\
\hline \multirow{2}{*}{ Post-test } & $\mathrm{CC}$ & 7.05 & 55 & 108 & 3.580 & .001 \\
\cline { 2 - 7 } & $\mathrm{EC}$ & 8.69 & 55 & 108 & 3.580 & .001 \\
\hline
\end{tabular}

According to the table 4, it depicts the means of the output of targeted connectives in pre-, mid- and post-test between CC and EC. In pre-test, the mean of EC with 7.64 is larger than $\mathrm{CC}$ that is 7.45. In mid-test, there is a sharp increase in $\mathrm{CC}$ that ranges from 7. 45 to 8.87 . On the contrary, EC experiences a decrease with 0.59 (7.64-7.05) rapidly. Regarding the means of $\mathrm{CC}$ and $\mathrm{EC}$ in post-test, there is an increasing tendency in EC with 8.69 compared with the means that is 7.05 in mid-test, which indicates POA has had certain positive influence on students' output of targeted connectives in EC. As for the mean of CC in post-test, it drops sharply with a decreasing point 1.82 (8.87-7.05) compared with the mean in mid-test. Moreover, there are significant differences between $\mathrm{CC}$ and $\mathrm{EC}$ in the light of the output of targeted connectives in mid- and post-test with the values being both 0.001 and 0.001 respectively that are both below 0.05 . In other words, the results suggest that POA is more helpful than PWA to facilitate students' output of targeted connectives.

In a nutshell, based on the table 4, conclusions are made that POA could be better to help students master the output of targeted connectives than PWA.

\subsubsection{Results and Analysis of Writing Scores}

Based on the analytic results of SPSS 17.0, the results of independent sample t-test of writing tests in pre-, mid- and post-test between CC and EC are shown in table 5 .

Table 5. Independent Sample t-Test of Writing Scores in Pre-, Mid- and Post-test between CC and EC

\begin{tabular}{|c|c|c|c|c|c|c|}
\hline & Class & $\mathrm{N}$ & Mean & $\mathrm{df}$ & $\mathrm{T}$ & $\begin{array}{c}\text { Sig. } \\
\text { (2-tailed) }\end{array}$ \\
\hline \multirow{3}{*}{ Pre-test } & $\mathrm{CC}$ & 55 & 11.72 & 108 & -0.993 & .323 \\
\cline { 2 - 7 } & $\mathrm{EC}$ & 55 & 11.30 & 108 & -0.993 & .323 \\
\hline \multirow{3}{*}{ Mid-test } & $\mathrm{CC}$ & 55 & 14.33 & 108 & -0.670 & .504 \\
\cline { 2 - 7 } & $\mathrm{EC}$ & 55 & 14.23 & 108 & -0.670 & .504 \\
\hline \multirow{2}{*}{ Post-test } & $\mathrm{CC}$ & 55 & 13.98 & 108 & -0.384 & .701 \\
\cline { 2 - 7 } & $\mathrm{EC}$ & 55 & 13.65 & 108 & -0.384 & .701 \\
\hline
\end{tabular}

The table 5 expounds writing scores in pre-, mid- and post-test between CC and EC. The mean writing scores of $\mathrm{CC}$ in the pre-test is 11.72 , which is a bit higher than that of $\mathrm{EC}$ with 11.30. Meanwhile, the significant value $(\mathrm{p}=0.323)$ in pre-test is greater than 0.05 , which implies the mean writing score of $\mathrm{CC}$ and $\mathrm{EC}$ is no significant difference. During the mid-test, clearly, the means of both classes have increased with different extent, just like EC with 2.93(14.23-11.30) and CC with 2.61 (14.33-11.72). Furthermore, the significant value $(\mathrm{p}=0.504)$ is still higher than 0.05 , which denotes there is no significant difference in writing scores between $\mathrm{CC}$ and $\mathrm{EC}$ in mid-test. Compared with mid-test, the means of writing in $\mathrm{CC}$ and EC have both decreased slightly in post-test. Furthermore, the significant value is 0.701 , which is much greater than 0.05 . In other words, there is no significant difference in terms of writing scores between $\mathrm{CC}$ and $\mathrm{EC}$.

According to the conclusions the above, it is consistent with Zhang [21] research results that the total scores of experimental class and control class are no significant difference.

\section{Conclusions}

First and foremost, compared with PWA, POA is more capable to motivate students to have a better command of English writing strategies significantly. 
Secondly, compared with PWA, there are significant differences between $\mathrm{CC}$ and $\mathrm{EC}$ in terms of language accuracy and the output of targeted connective usage rather than syntactic complexity of clause with the guidance of POA. In certain degree, the results are complied with Skehan's [6] standpoints; in other words, due to the distributions of learners' attention, they tend to concentrate on some aspects at the expense of others. Hence, when students pay more attention to language accuracy and the output of targeted connectives, then they will give much less attention to syntactic complexity of clause. More importantly, we cannot deny that PWA also has had certain significant influence on language accuracy, syntactic complexity of clause as well as the output of targeted connectives in $\mathrm{CC}$ at different stages.

Thirdly, compared with PWA, students' writing scores have no significant difference between $\mathrm{EC}$ and $\mathrm{CC}$ with the introduction of POA, and the result is the same as Zhang [21].

\section{REFERENCES}

[1] Brown, D., "English language teaching in the "Post-Method" era: Towards better diagnosis, treatment, and assessment," In J. C. Richards \& W. A. Renandya (eds.). Methodology in Language Teaching [C]. Cambridge, England: Cambridge University Press, 2000, pp. 9-18.

[2] Han, J. L., Qin, X. B., "Genre Analysis and Genre Teaching Method," Foreign Language World, no.1, pp. 11-18, 2000.

[3] Halliday, M. A. K., "An Introduction to Functional Grammar,”, London: Edward Arnold, 1985.

[4] Hunt, K., "Grammatical Structures Written at Three Grade Levels," Champaign, Ill: National Council of Teachers of English, 1965.

[5] Polio, C. G., "Second language development in writing: Measures of fluency, accuracy and complexity," Studies in Second Language Acquisition, no. 2, pp. 423-424, 2001.

[6] Skehan, P., Foster, P., Cognition, and tasks [A]. In P. Robinson (ed.). Cognition and Second Language Instruction [C]. New York: Cambridge University Press, 183-205,2001.

[7] Sheng, R. Z., Feng, T. J., “A Comparison of Traditional Writing Teaching Method and Lengthy Writing in College English," Journal of Southwest Agricultural University (Social Science Edition), no. 1, pp. 123-125, 2006.

[8] Tyler, R. W., "Basic Principles of Curriculum and Instruction," Chicago: The University of Chicago Press. 1949.

[9] Wang, C. M., Niu, R. Y., Zheng, X. X., "Promoting Learning by Writing: An Experiment of English Writing
Teaching Reform," Foreign Language Teaching and Research, no. 3, pp. 207-212, 2000.

[10] Wolfe-Quintero, K., Inagaki, S. \& Kim, H., "Second Language Development in Writing: Measures of Fluency, Accuracy \& Complexity, "Second Language Teaching \& Curriculum Center: University of Hawaii at Manoa, 1998.

[11] Wen, Q. F., “Advanced level English language learning in China: The relationship of modifiable learner variables to learning outcomes. Hong Kong University: Unpublished Ph.D. thesis, 1993.

[12] Wen, Q. F., “Output Driven Hypothesis and Curriculum Reform of English Majors," Foreign Language World, no. 2, pp. 2-9, 2008.

[13] Wen. Q. F., "Constructing the Theoretical System of 'Production-oriented Approach,", Foreign Language Teaching and Research, Vol. 47, no. 4, pp. 547-558,2015.

[14] Wen, Q. F., "The production-oriented approach to teaching university students English in China," Language Teaching, 2016.

[15] Wen, Q. F., "Teacher-student Collaborative Assessment": The New Form of Assessment of 'Production-oriented Approach'," Foreign Language World, no. 5, pp. 37-43, 2016.

[16] Wen, Q. F., "The production-oriented approach: A pedagogical innovation in university English teaching in china," In L. Wong \& K. Hyland (eds.). faces of English: students, teachers, and pedagogy [C]. London \& New York: Routledge, 2017, pp. 91-106.

[17] Wen, Q. F., "The Chinese Characteristic of 'Production-oriented Approach'," Modern Foreign Language, Vol. 40, no. 3, pp. 48-358+438, 2017.

[18] Wen, Q. F., "Teaching Materials Usage and Evaluation Theoretical Framework of 'Production-oriented Approach'," Foreign Language Education in China, Vol. 10, no. 2, pp. 17-23+95-96, 2017

[19] Zhang, W. J., "Class Teaching Pilot of College English based on 'Production-oriented Approach'," Foreign Language and Foreign Language Teaching, no. 2, pp. 106-114+147, 2016.

[20] Zhang, W. J., "Experimental Research of Influence of College English Writing of 'Production-oriented Approach'," Modern Foreign Language, Vol. 40, no. 3, pp. 377-385+438-439, 2017.

[21] Zhao, Y., "Application of Lexical Chunk Theory in English Writing of Senior High School,", 2009.

[22] Zhang, Y., Tao, L. J., “Analysis of Changing Approach of English Writing Ability based on 'Production-oriented Approach," Journal of Chinese Education, no. 3, pp. 137-139, 2018.

[23] Zhang, Y. P., "Measurement Factor and Methods of English Oral Communicative Task," Foreign Languages in China, Vol.4, no. 4, pp. 65-69, 2007 